\title{
Benchmarking of scaling and fouling of reverse osmosis membranes in a power generation plant of paper and board mill: an industrial case of a paper and board mill study
}

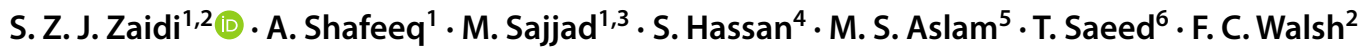

Received: 17 July 2020 / Revised: 1 October 2020 / Accepted: 31 October 2020 / Published online: 5 December 2020

(c) The Author(s) 2020

\begin{abstract}
The present study reports the characterization of reverse osmosis (RO) technology at water treatment plant Cogen-2 in paper and Board mills, Pakistan. RO is a commonly used process to obtain de-mineralized water for high-pressure boiler operation in thermal power plants. Scaling and fouling in three-stage RO plants is a major challenge in chemical industry due to the use of raw brackish water in the power plant of paper and board mills. In our study, the feed water quality of RO was changed from soft water to raw water to make it economical. The cleaning frequency was increased three times than normal, which was unsafe for operation and it was required to control scaling and fouling to achieve the desired result. Differential pressures behavior of all stages for 2-month data was observed without acid treatment, and the results of Langelier Saturation Index (LSI) control parameters (temperature, $\mathrm{pH}$, total dissolved solids, calcium hardness, and alkalinity) clearly showed the abnormality. To optimize scaling and fouling of RO, the LSI factor was controlled in total reject water for the next 2 months by acid treatment in feed water. Duration of chemical cleaning and membranes' life has been extended by fouling and scaling control. Understanding the effect of operational parameters in $\mathrm{RO}$ membranes is essential in water process engineering due to its broad applications in drinking water, sanitation, seawater, desalination process, wastewater treatment, and boiler feed water operation. The product flow increased from 18.3 to $19.9 \mathrm{~m}^{3} / \mathrm{h}$, and this was due to a decrease in the rejection flow from 8.2 to $6.7 \mathrm{~m}^{3} / \mathrm{h}$. The total reject stream pressure also increased from 8.1 to 9 bar. A lower value of LSI of 1.6 is obtained in the reject water stream after the acid treatment.
\end{abstract}

Keywords Acid treatment $\cdot$ LSI $\cdot$ Membrane $\cdot$ Reverse osmosis $\cdot$ Fouling

Editorial responsibility: Samareh Mirkia.

S. Z. J. Zaidi

zohaib.icet@pu.edu.pk

1 Institute of Chemical Engineering and Technology, University of the Punjab, Lahore, Pakistan

2 Electrochemical Engineering Laboratory, Energy Technology Research Group, Faculty of Engineering and Environment, Engineering Sciences, University of Southampton, Highfield, Southampton SO17 1BJ, UK

3 Paper \& Board Mills Ltd, Multan Road, Kasur, Pakistan

4 Mechanical Engineering, Faculty of Engineering and Environment, Engineering Sciences, University of Southampton, Highfield, Southampton SO17 1BJ, UK

5 Institute of Biochemistry and Biotechnology, University of the Punjab, Lahore, Pakistan

6 Department of Chemistry, Government Jinnah Degree College for Women, Lahore, Pakistan

\section{Introduction}

Raw water cannot be used directly in high-pressure boilers in steam turbine operation due to the total hardness and presence of higher concentrations of total dissolved solids and other salts and chlorides. These solids and salts can strongly corrode and scale in boiler tubes and must be removed prior to feed in the boilers (Ansari and Pandit 2020). In addition, scaling creates a barrier to heat transfer which results in higher fuel consumption and maintenance cost which are required to overcome all these issues (Das et al. 2018). To overcome these issues permanently, the feed water quality must be improved. There are a lot of methods for the treatment of raw water in order to maintain water quality and to obtain the desired results of different parameters $(\mathrm{pH}$, total dissolved solids (TDS), hardness, alkalinity, chlorides, silica, and iron) of boiler feed water. For example, there are electrochemical approaches (Zaidi et al. 2018, 2019), 
forward osmosis (Al Hawli et al. 2019), photocatalysis (Tran et al. 2020), nanofiltration (Shahriari and Hosseini 2020), capacitive deionization (Qin et al. 2019), and reverse osmosis. In reverse osmosis (RO) plant, water passes through a semi-permeable membrane from a higher concentration of salts to lower the concentration by applying force through the use of a high-pressure pump (Qasim et al. 2019). Product water is collected in the middle stream, and rejected water which has high salt concentration is collected in another stream. RO consumes relatively low energy as compared to other approaches (Park et al. 2020). Scaling and fouling in RO depend on the feed quality of water (Čuda et al. 2006).

Collection of deposition of particles on the surface of membranes is called membrane fouling. Fouling causes a decline in flux flow of RO and results in membrane damage requiring replacement due to permanent adsorption over the membrane surface. Significant types of fouling are organic, inorganic, and biological. There are different techniques which are used to control fouling on the membrane surface, including pretreatment, water softening, coagulation, and flushing. Usage of soft water for the RO plant enhances plant recovery and resolves the problem of scaling and fouling. To control fouling, residual chlorine removal and disinfection are frequently used. Oxygen removal from feed water can also reduce fouling in RO. The proper dosage rate of antiscalant and biocides help to control fouling and scaling. Till now, the mechanism of scaling and fouling has not been correlated with operating conditions like temperature, flow velocity, $\mathrm{pH}$, and total dissolved solids (TDS) (Al-Ahmad and Aleem 1993). Precipitation of hard minerals such as deposition of $\mathrm{CaSO}_{4}, \mathrm{CaCO}_{3}$, and silica on the surface of membranes is known as scale formation.

Several types of membranes have been developed to slow down the scaling such as spiral wound membranes offer slower scale formation than cross flow membranes (Lee and Lee 2005). In another development, Pramanik et al. (Pramanik et al. 2017) used polyaspartic acid and its derivative as an anti-scaling agent in lab-scale RO followed by examination of the used membrane using a scanning electron microscope (SEM) and x-ray diffraction XRD for determining the type of fouling. Tong et al. (2020) studied the characteristic of fouling (e.g., biofouling, inorganic, organic) in a two-stage industrial RO system for reclamation of wastewater. Yin et al. (2019) focused on the silica scaling and studied its relationship with membrane surface chemistry to enhance surface flux in a RO plant.

In this paper, the membrane distillation process was examined, and fouling techniques were used for the distillation process in a real industrial setting. Fouling mechanism was discussed by the usage of brackish water. Moreover, a three-stage filtration RO plant was used in which the trend of fouling and scaling was different from two-stage or singlestage RO plants operated at the same feed water quality.
Recovery and water quality of plants were changed in correlation with stages and as well scale formation tendency (Bonné et al. 2000; Hoek et al. 2000). The effectivity of acid treatment in this work was benchmarked using Langelier Saturation Index (LSI) value which is widely used in an industrial setting for examining scale formation mostly calcium carbonate.

\section{Material and methods}

Experiments were carried out on a three-stage RO plant (Fig. 1) installed at water treatment plant Cogen-2 in paper and Board mills (PBM) Limited, Pakistan. Water testing was performed in a PBM water lab, Pakistan. The RO plant which was chosen for experimentation has a capacity of 20 tonnes/h product flow and 6.6 tonnes/h flow discharge in the reject water stream. This RO plant has raw water, high-pressure pump, and pre-filtration including multimedia filter and cartridge filter of 5 and 1 microns, respectively. Feed, product, and reject flow meter was installed to measure the flow rate. Scaling and fouling have been controlled by reducing feed velocity. Another treatment suggested was the usage of caustic regime instead of lime for brackish water. The concentration of feed water was changed by changing the softening process. In this way, permeate flow remained constant over a long period (Amiri and Samiei 2007).

Sulfuric acid (98\%) and antiscalants were added at 0.28 and $3 \mathrm{ppm}$, respectively, to the RO feed to moderate the Langelier Saturation Index (LSI) value in the concentrate stream to $<2$, and the plant was safely operated up to recovery of $85 \%$ without any $\mathrm{BaSO}_{4}$ scale formation. Daily consumption of sulfuric acid and antiscalant was 10 and $2 \mathrm{~kg}$ per day.

Sulfuric acid is preferred over $\mathrm{HCl}$ due to environmental impact and less cost consumption. An organophosphate biopolymer antiscalant, HDC-ASI-ECO1, which is a biodegradable antiscalant, was provided by Hatenboer-water Rotterdam, Netherlands. Pressure gauges were installed on all stages, as shown in Fig. 1. LSI factor was used to calculate the tendency of scaling. This equilibrium model is derived from the theoretical concept of saturation, and it provides an indicator of the degree of saturation of water in $\mathrm{CaCO}_{3}$. The LSI was calculated using the equation provided by Antony et al. (2011). The product was collected in the middle stream and stored in a 400-tonnes capacity RO tank, while reject water was collected in the concentrated stream.

Membranes were installed in the RO plant with the specifications provided in Table 1. Each stage had an individual sample point, as shown in Fig. 1. Water samples were collected from the feed of first, second, third stage, and total reject of RO. The temperature was calculated with a simple thermometer while for $\mathrm{pH}$ and TDS testing, 
Fig. 1 Experimental setup of three-stage RO Plant. The raw water is pumped through filters and doses of biocide, antiscalant, and sulfuric acid are added before it is introduced in the RO tank

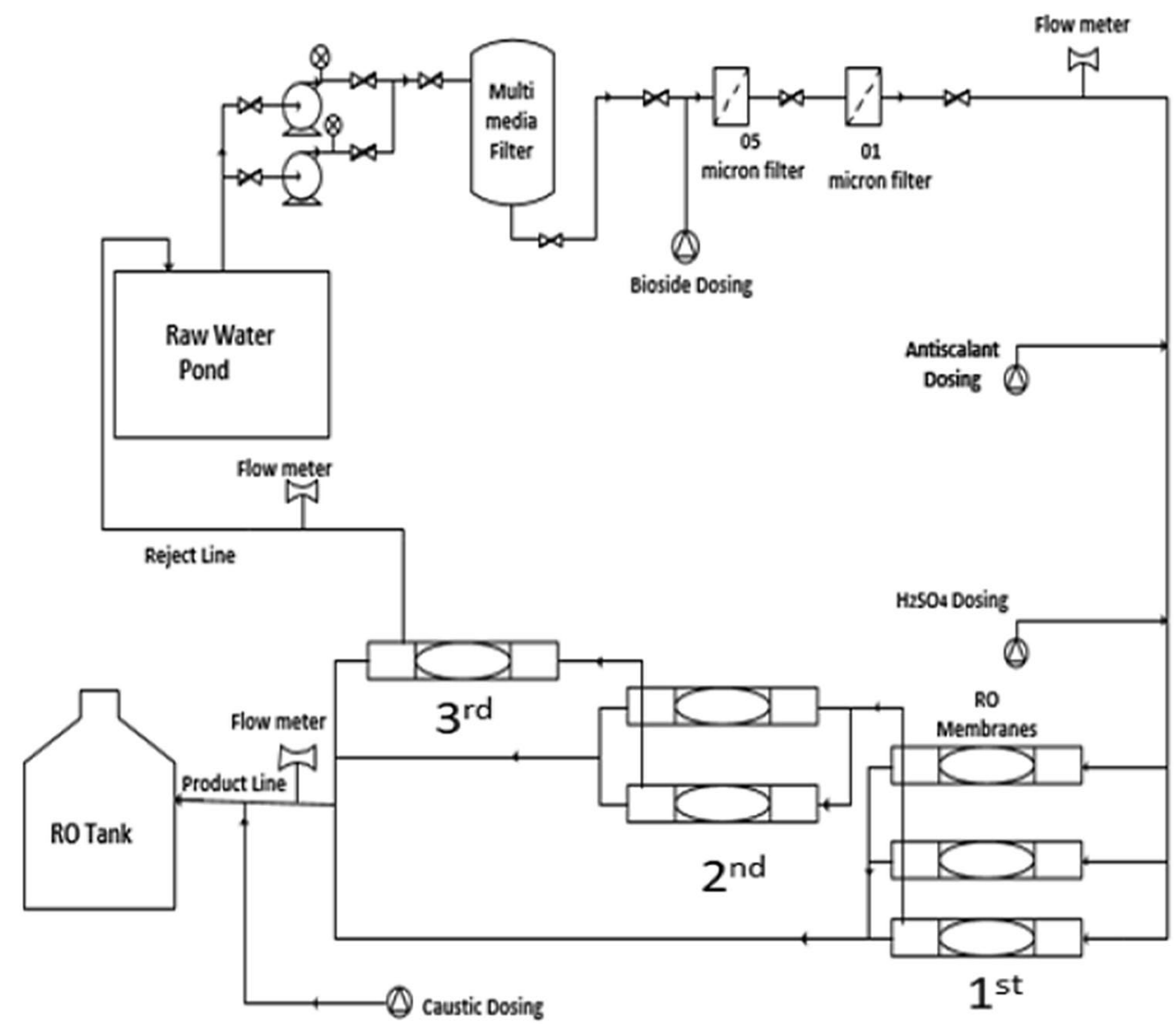

Table 1 Specification and characterization of RO plant

\begin{tabular}{ll}
\hline Product & BW30-400 \\
\hline Part number & 98,650 \\
Active area $\mathrm{ft}^{2}\left(\mathrm{~m}^{2}\right)$ & $400(37)$ \\
Feed spacer thickness (mil) & 28 \\
Permeate flow rate gpd $\left(\mathrm{m}^{3} / \mathrm{d}\right)$ & $10,500(40)$ \\
Stabilized salt rejection $(\%)$ & $99.50 \%$ \\
Minimum salt rejection $(\%)$ & $99 \%$ \\
Membrane type & Polyamide thin- \\
& film composite \\
Max operating temperature & $113 \mathrm{~F}(45 \mathrm{C})$ \\
Max operating pressure & $600 \mathrm{psig}(41 \mathrm{bar})$ \\
Max pressure drop & $15 \mathrm{psig}(1 \mathrm{bar})$ \\
pH range, continuous operation & $2-11$ \\
pH range, short-term cleaning & $1-13$ \\
Max feed flow & $19 \mathrm{~m}^{3} / \mathrm{hr}$ \\
Max feed silt density index & 5 \\
Free chlorine tolerance & $<0.1 \mathrm{ppm}$ \\
\hline
\end{tabular}

the meter of HANNA (model \# HI 83,141, HI 8734) was used. LSI factors (calcium hardness and alkalinity) were calculated by the titration method in the lab.

\section{Results and discussion}

\section{Benchmarking of RO plant without acid treatment}

\section{Effect of pressure of RO plant at different stages with time}

Figure 2 shows an increase of pressures at all the stages of RO plant rapidly with the passage of time as compared to expected pressures. The RO plant was operated at $75 \%$ recovery, and the trend of increase in pressures was found to be very rapid, which was caused by fouling and scaling of membrane abruptly. This, in turn, resulted in an increase in cleaning frequency. Repeated cleaning of RO membranes increased to TDS which caused a decline in salt rejection. The first-stage pressure of RO increased from 8.8 to 10.6 bar having a pressure drop of 1.8 bar and increased linearly. Similarly, the second- and third-stage pressures were also increased.

Figure 2 describes the increase of pressure due to cake formation on the membrane surface and in the first stage almost $20 \%$ increase in pressure was observed while in second, third stage, and total reject increase of pressures was found to be $23 \%, 30 \%$, and $44 \%$ of initial values, respectively, over 2 months. In the second and third stages, the increase in pressures was relatively higher as compared to the first stage. Feed water had a high concentration of salts 


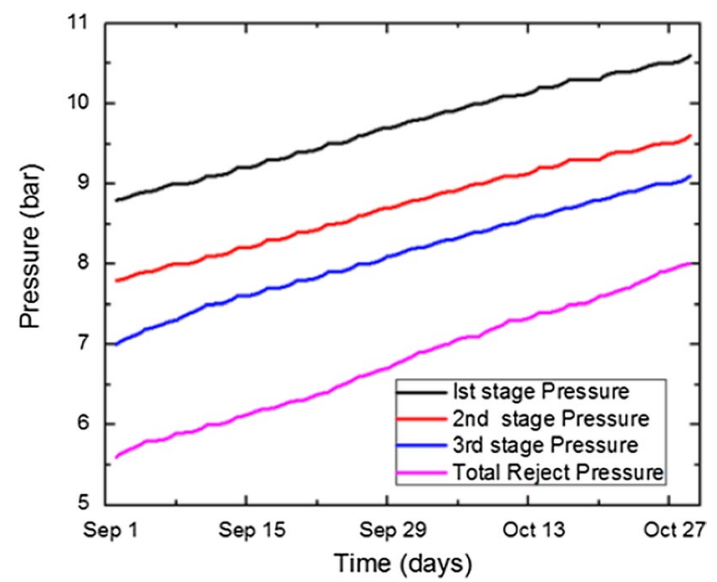

Fig. 2 Effect of pressure curve of all stages against time for RO plant. The pressure increase is significant at each pressure stage. The salt concentration is higher at high pressure stage

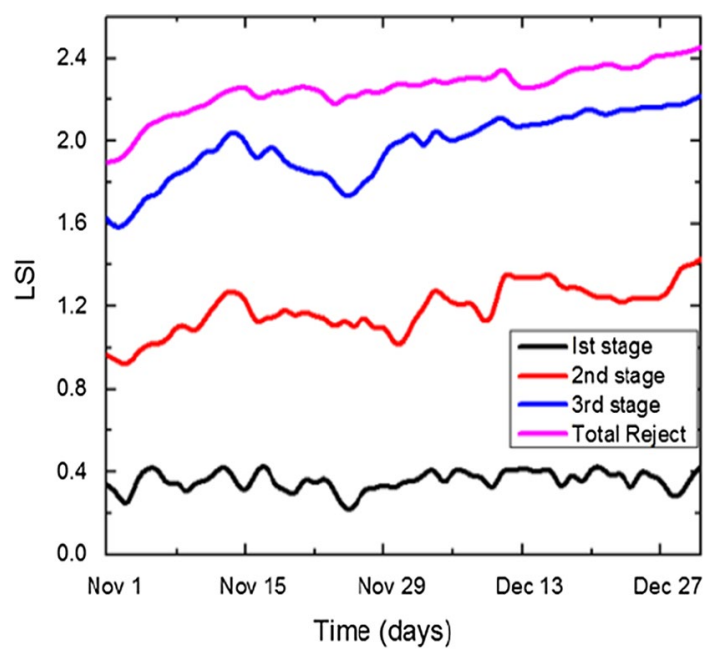

Fig. 3 LSI factor on RO membrane with time before acid treatment. High LSI values are observed for every stage, including the total reject. LSI factor on RO membrane with time in the second and third stages. Fouling and scaling phenomenon occurred more rapidly in these stages.

\section{Effect of LSI factor against time}

Figure 3 shows clearly LSI values of all stages of RO without acid plotting against time. In normal operation, when LSI factor was calculated, it resulted in high LSI values of all stages, particularly total reject where its LSI Value went up to 2.5. Due to the high LSI factor, RO membranes caused scaling and fouling rapidly and resulted in a rapid increase of RO pressures. Rapidly increased pressures and product flow drop needed chemical cleaning of RO membranes. Thus, RO membranes were cleaned repeatedly in order to normalize the pressure and product flow (Hoek et al. 2000).

\section{Benchmarking of RO plant after acid treatment}

Sulfuric acid started to dose in the feed line of RO. Table 2 clearly shows that after acid treatment product flow started to recover instead of dropped while pressures increment was normal during 2 months in Table 3. Therefore, scaling and fouling have been optimized as per regular operation. From Table 2, we can see that due to the acid treatment that has been applied to the raw water; the reject flow is constantly being reduced from 8.2 to $6.7 \mathrm{~m}^{3} / \mathrm{h}$, while the product flow is increased from 18.4 to $19.9 \mathrm{~m}^{3} / \mathrm{h}$. The pressure at each stage is also increased, as we can see from Table 3. The increase in pressure is due to the flow increase in the product flow. Tables 2 and 3 show that the acid treatment has improved the efficiency of the whole operation.

\section{Effect of pressure of RO plant with time}

Pressures of all stages with the passage of time did not increase abruptly as increased without acid addition, as shown in Fig. 4. Acid treatment is effective in such a way that pressure increment of first stage was $7.5 \%$ which was
Table 2 Effect of flow rates during 2 months with acid treatment

\begin{tabular}{llllllll}
\hline Date & 1-Nov-19 & 10-Nov-19 & 20-Nov-19 & 30-Nov-19 & 9-Dec-19 & 19-Dec-19 & 29-Dec-19 \\
\hline Feed flow $\left(\mathrm{m}^{3} / \mathrm{h}\right)$ & 26.6 & 26.6 & 26.6 & 26.6 & 26.6 & 26.6 & 26.6 \\
Product $\left(\mathrm{m}^{3} / \mathrm{h}\right)$ & 18.4 & 18.6 & 18.9 & 19.2 & 19.5 & 19.7 & 19.9 \\
Reject flow $\left(\mathrm{m}^{3} / \mathrm{h}\right)$ & 8.2 & 8 & 7.7 & 7.4 & 7.1 & 6.9 & 6.7 \\
\hline
\end{tabular}

Table 3 Effect of pressures of all stages during 2 months with acid treatment

\begin{tabular}{lllllllll}
\hline Date & & 1-Nov-19 & 10-Nov-19 & 20-Nov-19 & 30-Nov-19 & 9-Dec-19 & 19-Dec-19 & 29-Dec-19 \\
\hline First-stage pressure & Bar & 10.6 & 10.7 & 10.9 & 11 & 11.1 & 11.3 & 11.4 \\
Second-stage pressure & Bar & 9.6 & 9.7 & 9.9 & 10 & 10.1 & 10.3 \\
Third-stage pressure & Bar & 9.1 & 9.2 & 9.4 & 9.5 & 9.6 & 9.9 & 10.4 \\
Total reject pressure & Bar & 8.1 & 8.2 & 8.4 & 8.5 & 8.6 & 8.9 & 9 \\
\hline
\end{tabular}




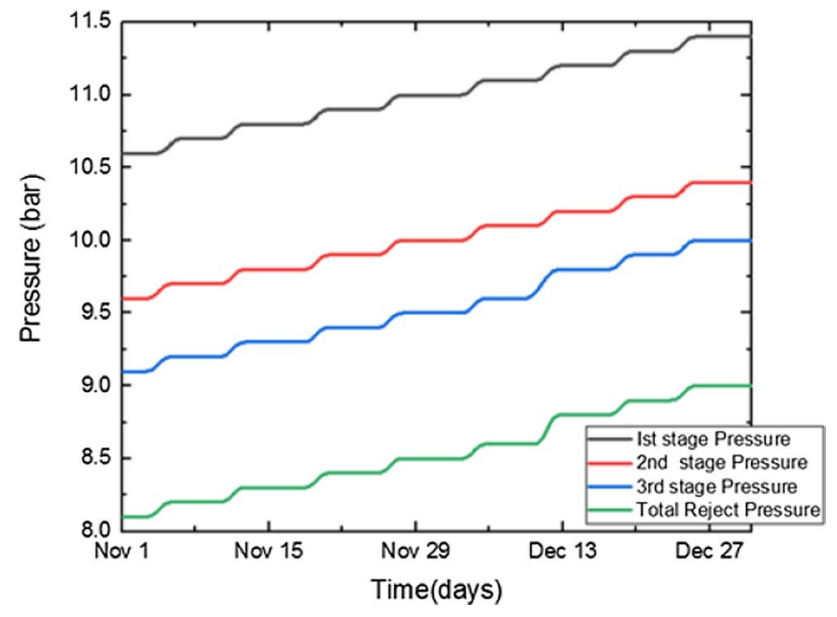

Fig. 4 Effect of optimized pressure curve of all stages against time for RO plant after acid treatment. The pressure increases at each stage, but it is not a huge change from the pressure which is observed without the acid treatment

reduced three times. Pressure increment in the second stage, third stage, and total reject was $8.3 \%, 9.8 \%$ and $11.1 \%$ respectively. Cleaning frequency and operational cost were reduced while maintaining the quality of permeate (Redondo and Lomax 2001).

\section{Effect on LSI factor after acid treatment}

Figure 5 shows the controlled LSI value by $\mathrm{H}_{2} \mathrm{SO}_{4}$ addition in the feed line to reduce $\mathrm{pH}$ from 7.6 to 7.2. Lowering the $\mathrm{pH}$ resulted in a lower value of LSI (1.6) in total reject. This controlled LSI factor resulted in minimizing the formation of

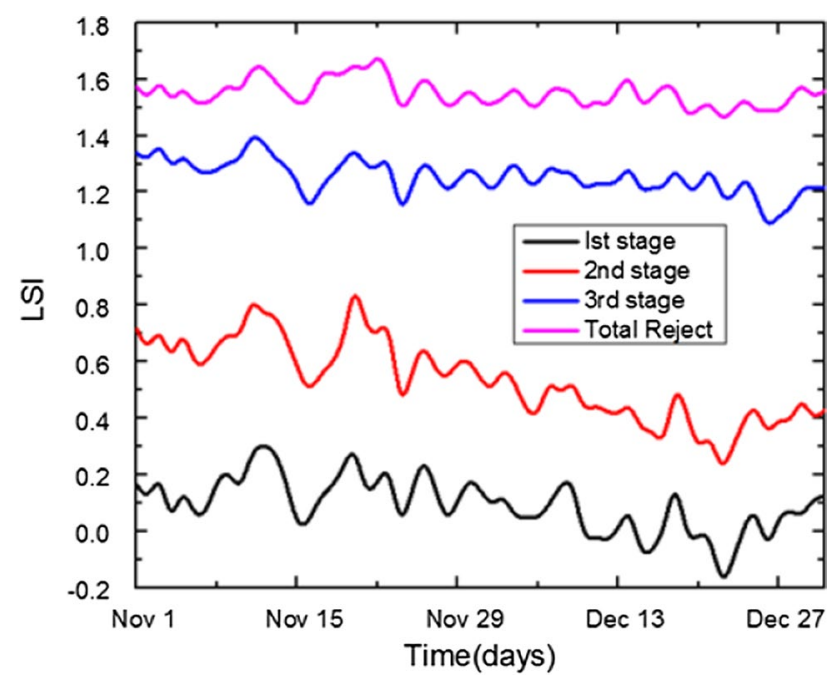

Fig. 5 LSI factor at RO membrane after acid addition with time. The scaling and fouling in RO membrane is reduced due to the acid treatment scaling and fouling in RO membranes. Hence, pressures of all stages did not increase rapidly (ASTM D3739-19 2019).

\section{Free mineral acidity and $\mathrm{pH}$ at cation exchanger}

Free mineral acidity (FMA) can be measured by the anions of strong acids, namely sulfuric, nitric, and hydrochloric acid, which is free to react at the outlet of the cation exchanger (Ramzan et al. 2012). In Fig. 6, a stable FMA value around 52 was observed due to the injection of sulfuric acid during acid treatment in the feed line. All the anions of strong acid were filtered at the primary anion exchanger, which was shown the value of FMA reduced to 0 at the primary anion exchanger outlet. This shows that the ion exchangers are relatively stable over time and there was no leakage at the primary anion exchanger. The $\mathrm{pH}$ at the cation exchanger was significantly decreased from about 7.7 to 2.9 due to acid injection, which is shown in Fig. 7. These $\mathrm{pH}$ values are still within the operational range of the RO plant, which is $2-11$ for continuous operation, as given in Table 1 .

\section{Effect of permeate water flow rate with time}

Figure 8 shows clearly that product flow decreased with the passage of time due to fouling and scaling on RO membranes and resulted in a decrease of permeate flux as well as recovery rate. It clearly indicates that flux declined on the surface of the RO membrane was due to crystal formation and these crystals caused fouling and scaling by which hindrance to feed water, and it caused decease in permeate water. Flux decline mechanism involved in the crystalline layer formation on the porous surface of membranes (Brusilovsky et al. 1992).

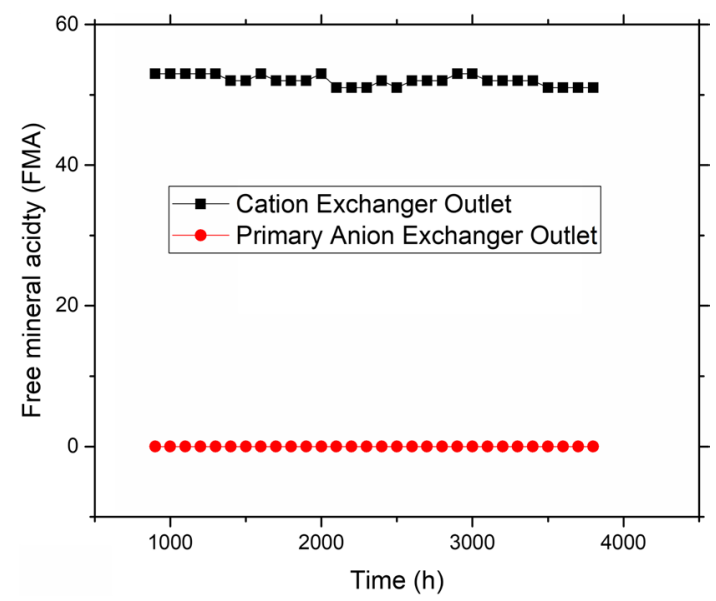

Fig. 6 Free mineral acidity (FMA) versus time. Both cation exchanger outlet and primary anion exchanger outlet values remain extremely stable over a long period of time 


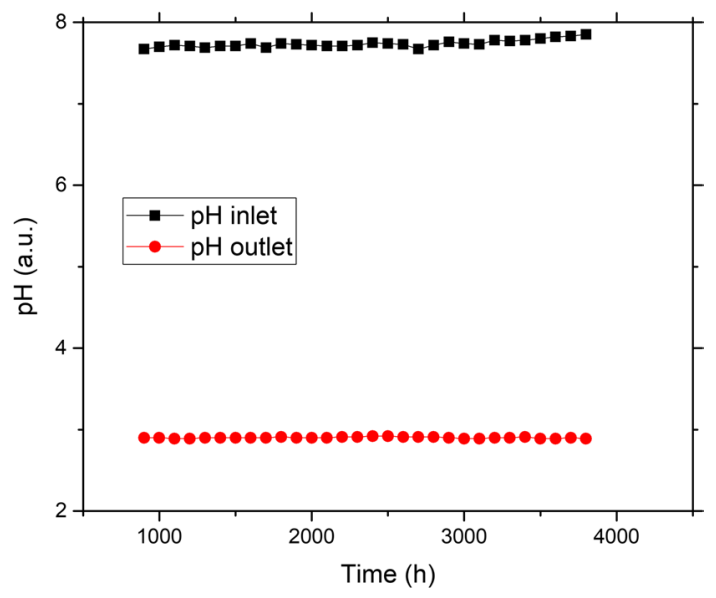

Fig. 7 The graph of $\mathrm{pH}$ at the cation exchanger versus time. The $\mathrm{pH}$ outlet is extremely stable, while the inlet $\mathrm{pH}$ shows a slight increase over a long period of time

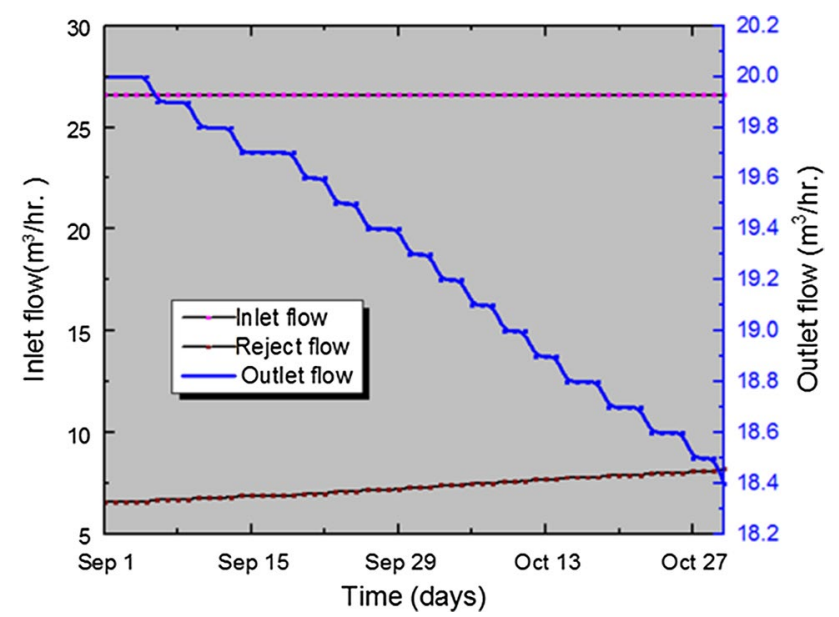

Fig. 8 Effect of flow rate at the inlet and outlet of the RO membrane with time. The outlet flow decrease over time is significant. The outlet flow increase causes an increase in reject flow in RO membrane

\section{Effect of reject water flow rate with time}

It is obvious from Fig. 8 that with the passage of time, highly concentrated water was not allowed to pass through the membrane pores, and it was directed into the reject stream. Therefore, fouling and scaling occurred and ultimately reject flow increased (Radu et al. 2012). The RO membrane was unable to handle the increased flow of highly concentrated water, this resulted in the increase of the Rejected water, which also caused more scaling. This resulted in a vicious circle, which is due to constant increasing scaling, the RO membrane becomes less and less effective, which causes more scaling and so on.

\section{Effect of feed TDS with permeate TDS against time}

Feed water quality directly affected the product. Higher TDS in feed resulted in higher TDS in the product, as shown in Fig. 9. For this reason, a high concentration of salts in feed was rejected by membranes and collected in the concentrate stream. These salts increased load on the membrane surface, and hence membrane permeates water quality automatically increased correspondingly (Sridhar 2002).

\section{The normalized concentration of salt in reject water against time}

The concentration of sodium, potassium, chloride, and sulfate ions was measured at the reject water tank, as shown in Fig. 10. It was found that breakthrough of several ions such as sodium, potassium, and sulfate can be observed, and the normalized concentrations were increased by $6.12 \%, 6.06 \%$, and $2.52 \%$ from 900 to $2400 \mathrm{~h}$ for sulfate, potassium, and sodium ions, respectively. On the other hand, no chloride ion leakage was found. The salt leakage may lead to calcium carbonate scaling formation due to the following reactions.

$$
\begin{aligned}
& \mathrm{CaCl}_{2(\mathrm{aq})}+\mathrm{Na}_{2} \mathrm{CO}_{3(\mathrm{aq})} \rightarrow \mathrm{Ca}_{2} \mathrm{CO}_{3(\mathrm{~s})}+\mathrm{NaCl}_{(\mathrm{aq})} \\
& \mathrm{CaCl}_{2(\mathrm{aq})}+\mathrm{K}_{2} \mathrm{CO}_{3(\mathrm{aq})} \rightarrow \mathrm{Ca}_{2} \mathrm{CO}_{3(\mathrm{~s})}+\mathrm{KCl}_{(\mathrm{aq})}
\end{aligned}
$$

$\mathrm{CaCl}_{2}, \mathrm{Na}_{2} \mathrm{CO}_{3}$, and $\mathrm{K}_{2} \mathrm{CO}_{3}$ are soluble in water while $\mathrm{Ca}_{2} \mathrm{CO}_{3}$ is not soluble, creating precipitate or scaling (Jimoh et al. 2018). Due to no leakage in chloride ion, those breakthrough values still met the operational condition in which the recommended LSI is below 1.8 by the industrial standard

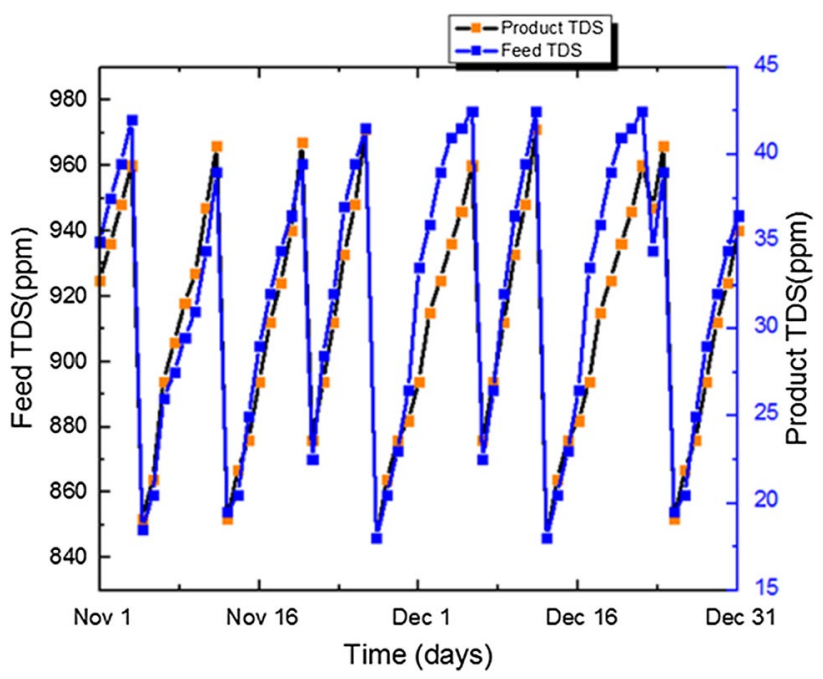

Fig. 9 Effect of TDS at the inlet and outlet of the RO membrane with time. The product and Feed TDS are almost the same. This is due to the feed TDS having an impact on the product TDS 


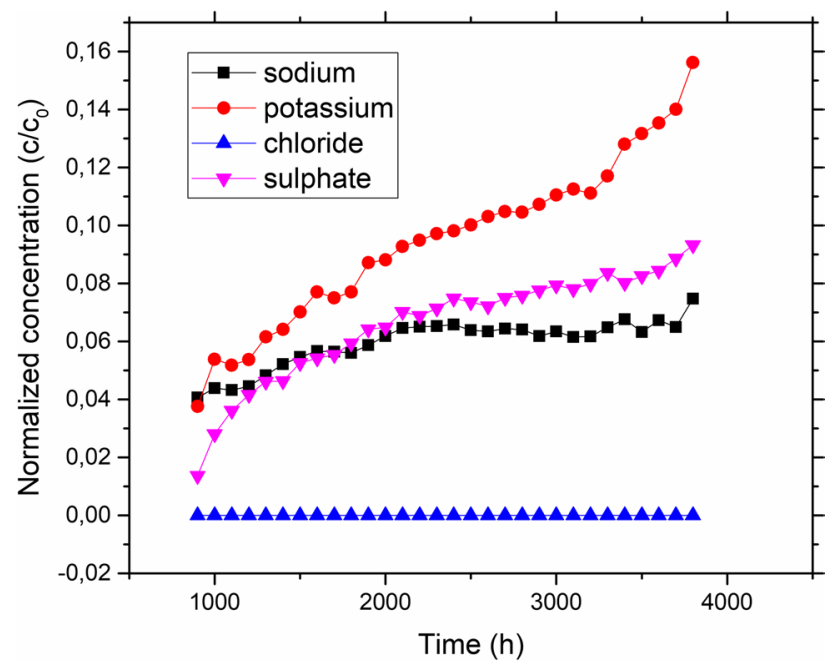

Fig. 10 Normalized concentration of salt in reject water versus time. The concentration of only Chloride remains the same and the concentration of every chemical increases over time in the rejected water

(Kucera 2015). The LSI value was found to be below 1.5 at the third stage in Fig. 3, meaning some scale formation occurred but still was at acceptable levels. Washing of membrane was minimized; hence, the quality of membrane for salt rejection can be preserved.

This study was focused on RO plant utilization, and different parameters related to the efficiency and operational analysis of parameters inlet and outlet of total dissolved solids, flow rates, LSI factor and thus the same meaningful results were concluded. As shown in results that designed RO three-stage plant in which first stage feed was rejected as a feed to second stage, and second stage was rejected to the feed of third stage. It was concluded that feed of the third stage of RO contained higher TDS, hardness in terms of $\mathrm{CaCO}_{3}$, and total alkalinity. In the third stage, membrane load seemed to be higher than the other two stages. Due to the presence of higher salt concentration, the membrane fouling and scaling were seen. It was concluded that the rapid increase in pressure of all stages is due to membrane fouling and scaling in the RO plant. Hence, the LSI value depends on various factors (temperature, $\mathrm{pH}$, TDS, calcium hardness, and total alkalinity) which can be controlled by changing these parameters.

In this research, $\mathrm{pH}$ value was adjusted by the addition of $\mathrm{H}_{2} \mathrm{SO}_{4}$ to control LSI and to avoid rapid fouling and scaling on the surface of membranes. It was obvious that under acidic condition, $\mathrm{CaCO}_{3}$ was dissolved and reduction in alkalinity minimized the effect of pressure; fouling and scaling were controlled, which resulted in normalization of cleaning frequency. Keeping in view the results; pressures, flow rate, and LSI value changed after acid treatment in all stages of the RO plant. Three-stage RO unit with high LSI value in total reject water stream more than 2.5 , resulted in fouling and scaling in membrane and pressures of all stages got higher subsequently. In order to control the LSI value, sulfuric acid had been dosed in the feed line and maintained $\mathrm{pH}$ up to 7.2 or 7.3. Ultimately, the LSI value was obtained $<1.5$. Hence, by controlling of LSI value, fouling and scaling of RO-Membranes were optimized. Therefore, instead of a change of $\mathrm{pH}$ of feed water, alternate options are available that we can change temperature, calcium hardness, and total dissolved solids of feed water in order to reduce fouling and scaling in the RO membrane.

Water consumption is increasing day by day as the availability of clean water is shortened. The RO is the heart of the desalination process. Therefore, it is necessary to enhance the life of RO plants. Further research is required in this field due to its severity. In two-stage RO, fouling and scaling trends are to a smaller extent as compared to three-stage plant due to less concentrations of salts in the reject stream. Thus, the LSI value will be $<1.5$ in the total reject of twostage RO and ultimately fouling and scaling will be controlled. Hence, it is an alternate solution of optimization of fouling and scaling on RO membranes to change its design.

\section{Conclusion}

In the current paper, the reverse osmosis (RO) technology is used to improve the water treatment processing of a paper manufacturing plant. The same process can be applied to improve water processing in every industry where water is used. To study the improvements in the treatment of raw water, a before and after method was used to see how the $\mathrm{RO}$ and the chemical used have improved the processing of the raw water. There is a significant improvement in both the processing and efficiency of the raw water. The process increased the amount of the treated water which is obtained at the output and decreased the rejected outflow which is waste. The improved water flow caused increase in scaling at the RO membrane which decreased the overall efficiency of the process. The addition of acid improves the efficiency of the water treatment process while also maintaining the quality of the water obtained in the product flow.

Acknowledgments The authors wish to thank all who assisted in conducting this work.

\section{Compliance with ethical standards}

Conflict of interest The authors declare no conflict of interest.

Open Access This article is licensed under a Creative Commons Attribution 4.0 International License, which permits use, sharing, adaptation, distribution and reproduction in any medium or format, as long as you give appropriate credit to the original author(s) and the source, 
provide a link to the Creative Commons licence, and indicate if changes were made. The images or other third party material in this article are included in the article's Creative Commons licence, unless indicated otherwise in a credit line to the material. If material is not included in the article's Creative Commons licence and your intended use is not permitted by statutory regulation or exceeds the permitted use, you will need to obtain permission directly from the copyright holder. To view a copy of this licence, visit http://creativecommons.org/licenses/by/4.0/.

\section{References}

Al-Ahmad M, Aleem FA (1993) Scale formation and fouling problems effect on the performance of MSF and RO desalination plants in Saudi Arabia. Desalination 93:287-310. https://doi. org/10.1016/0011-9164(93)80110-9

Al Hawli B, Benamor A, Hawari AA (2019) A hybrid electro-coagulation/forward osmosis system for treatment of produced water. ChemEng Process ProcessIntensif 143:107621. https://doi. org/10.1016/j.cep.2019.107621

Amiri MC, Samiei M (2007) Enhancing permeate flux in a RO plant by controlling membrane fouling. Desalination 207:361-369. https ://doi.org/10.1016/j.desal.2006.08.011

Ansari SZ, Pandit AB (2020) Inhibition of gypsum scales on MS metal surface using hydrodynamic forces. ChemEng Process ProcessIntensif 147:107706. https://doi.org/10.1016/j.cep.2019.107706

Antony A, Low JH, Gray S, Childress AE, Le-Clech P, Leslie G (2011) Scale formation and control in high pressure membrane water treatment systems: a review. J MembrSci 383:1-16. https://doi. org/10.1016/j.memsci.2011.08.054

ASTM D3739-19 (2019) Standard practice for calculation and adjustment of the Langelier saturation index for reverse osmosis. ASTM International, West Conshohocken. www.astm.org

Bonné PAC, Hofman JAMH, van der Hoek JP (2000) Scaling control of RO membranes and direct treatment of surface water. Desalination 132:109-119. https://doi.org/10.1016/S0011-9164(00)00140-5

Brusilovsky M, Borden J, Hasson D (1992) Flux decline due to gypsum precipitation on RO membranes. Desalination 86:187-222. https ://doi.org/10.1016/0011-9164(92)80033-6

Čuda P, Pospíšil P, Tenglerová J (2006) Reverse osmosis in water treatment for boilers. Desalination 198:41-46. https://doi. org/10.1016/j.desal.2006.09.007

Das P, Khan MMK, Rasul MG, Wu J, Youn I ( 201) Experimental investigation of hydrodynamic and heat transfer effects on scaling in an agitated tank. ChemEng Process ProcessIntensif 128:245256. https://doi.org/10.1016/j.cep.2018.04.019

Jimoh OA, Ariffin KS, Hussin HBB, Temitope AE (2018) Synthesis of precipitated calcium carbonate: a review. Carbonates Evaporates 33:331-346. https://doi.org/10.1007/s13146-017-0341-x

Kucera J (2015) Reverse osmosis: industrial processes and applications, 2nd edn. Scrivener Publishing LLC, Salem

Lee S, Lee CH (2005) Scale formation in NF/RO: mechanism and control. Water SciTechnol 51:267-275. https://doi.org/10.2166/ wst.2005.0646

Park K, Kim J, Yang DR, Hong S (2020) Towards a low-energy seawater reverse osmosis desalination plant: A review and theoretical analysis for future directions. J MembrSci 595:117607. https:// doi.org/10.1016/j.memsci.2019.117607
Pramanik BK, Gao Y, Fan L, Roddick FA, Liu Z (2017) Antiscaling effect of polyaspartic acid and its derivative for RO membranes used for saline wastewater and brackish water desalination. Desalination 404:224-229. https://doi.org/10.1016/j.desal.2016.11.019

Qasim M, Badrelzaman M, Darwish NN, Darwish NA, Hilal N (2019) Reverse osmosis desalination: a state-of-the-art review. Desalination 459:59-104. https://doi.org/10.1016/j.desal.2019.02.008

Qin M, Deshmukh A, Epsztein R, Patel SK, Owoseni OM, Walker WS, Elimelech M (2019) Comparison of energy consumption in desalination by capacitive deionization and reverse osmosis. Desalination 455:100-114. https://doi.org/10.1016/j.desal.2019.01.003

Radu AI, Vrouwenvelder JS, van Loosdrecht MCM, Picioreanu C (2012) Effect of flow velocity, substrate concentration and hydraulic cleaning on biofouling of reverse osmosis feed channels. ChemEng J 188:30-39. https://doi.org/10.1016/j.cej.2012.01.133

Ramzan N, Feroze N, Kazmi M, Ashraf M, Hasan S (2012) Performance analysis of cation and anion exchangers in water treatment plant: an industrial case study. Polish J ChemTechnol 14:35-41. https://doi.org/10.2478/v10026-012-0068-3

Redondo JA, Lomax I (2001) Y2K generation FILMTEC RO membranes combined with new pretreatment techniques to treat raw water with high fouling potential: summary of experience. Desalination 136:287-306. https://doi.org/10.1016/S0011 $-9164(01) 00192-8$

Shahriari HR, Hosseini SS (2020) Experimental and statistical investigation on fabrication and performance evaluation of structurally tailored PAN nanofiltration membranes for produced water treatment. ChemEng Process ProcessIntensif 147:107766. https://doi. org/10.1016/j.cep.2019.107766

Sridhar S (2002) Reverse osmosis of edible vegetable oil industry effluent. J MembrSci 205:83-90. https://doi.org/10.1016/S0376 -7388(02)00065-0

Tong X, Cui Y, Wang Y-H, Bai Y, Yu T, Zhao X-H, Ikuno N, Luo H-J, $\mathrm{Hu} \mathrm{H}-\mathrm{Y}, \mathrm{Wu} \mathrm{Y}-\mathrm{H}$ (2020) Fouling properties of reverse osmosis membranes along the feed channel in an industrial-scale system for wastewater reclamation. Sci Total Environ 713:136673. https ://doi.org/10.1016/j.scitotenv.2020.136673

Tran D-T, Mendret J, Méricq J-P, Faur C, Brosillon S (2020) Study of permeate flux behavior during photo-filtration using photocatalytic composite membranes. ChemEng Process ProcessIntensif 148:107781. https://doi.org/10.1016/j.cep.2019.107781

van der Hoek JP, Hofman JAMH, Bonné PAC, Nederlof MM, Vrouwenvelder HS (2000) RO treatment: selection of a pretreatment scheme based on fouling characteristics and operating conditions based on environmental impact. Desalination 127:89-101. https ://doi.org/10.1016/S0011-9164(99)00195-2

Yin Y, Wang W, Kota AK, Zhao S, Tong T (2019) Elucidating mechanisms of silica scaling in membrane distillation: effects of membrane surface wettability. Environ Sci Water Res Technol 5:204214. https://doi.org/10.1039/C9EW00626E

Zaidi SZJ, Harito C, Walsh FC, Ponce de León C (2018) Decolourisation of reactive black-5 at an $\mathrm{RVC}$ substrate decorated with $\mathrm{PbO}_{2} /$ $\mathrm{TiO}_{2}$ nanosheets prepared by anodic electrodeposition. J Solid State Electrochem 22:2889-2900. https://doi.org/10.1007/s1000 8-018-3992-1

Zaidi SZJ, Walsh FC, Harito C (2019) Mass transport control of oxygen reduction at graphite felt with subsequent decolourization of RB-5 dye in a parallel plate flow reactor. J Taiwan InstChemEng 104:123-129. https://doi.org/10.1016/j.jtice.2019.08.020 